\title{
UK welcomes help from Japan
}

\section{Tokyo \& London}

THE Japanese government is on the verge of investing several million pounds in the United Kingdom for two joint research projects. One was discussed by Prime Minister Toshiki Kaifu and Prime Minister Margaret Thatcher on 12 January during Kaifu's visit to Europe and an agreement is expected to be signed next month. The other is still under negotiation.

The project discussed by Kaifu and Thatcher is the first of a new international research programme funded by the Research and Development Corporation of Japan (JRDC), an affiliate of the Science and Technology Agency (STA). The new programme, which began this fiscal year, is modelled on JRDC's small but successful Exploratory Research for Advanced Technology (ERATO) programme (Nature 338, 532; 1989).

The project, to be called the 'Atom Arrangement Design and Control Project', will be carried out at the University of Cambridge and at the Interdisciplinary Research Centre on semicondcutor materials at Imperial College, London, in collaboration with the National Research Institute for Metals (NRIM) in Japan. A joint team of UK and Japanese researchers at Imperial College will investigate layerby-layer growth of semiconductor films by molecular beam epitaxy. Another team at Cambridge will study the microstructure of high performance alloys, for example aluminium alloys used in aircraft turbine

\section{DARPA}

\section{Neural network funding in doubt}

\section{Washington}

A 'miscommunication' between Congress and the Defense Advanced Research Projects Agency (DARPA) could result in a major cutback for neural network research in 1990. Congress last year stipulated that the Defense Department programme was to get \$20 million this year from 'reallocated' 1989 funds. But when DARPA officials prepared to distribute the money earlier this month, it became quickly apparent that there were no funds to be had, says programme director Barbara Yoon. The agency is looking for alternative funding from elsewhere in the Defense Department, but Yoon says that "it's safe to say that the programme will have to be scaled back" for the year. She emphasizes, however, that the cutback should not be interpreted as a lack of enthusiasm within DARPA for neural network research.

Yoon could not say how many grants have already been approved, or how many will be cancelled. G. Christopher Anderson blades.

Final details of the project, which is expected to last five years with a budget of about $£ 10$ million, have yet to be settled. But it appears that the United Kingdom will have to produce little or no new funding for the project. Rather, JRDC will accept 'funding in kind' in the form of research facilities and resources as the United Kingdom's 50 per cent contribution. Japan will provide postdoctoral researchers and cash for new equipment.

JRDC initially approached the US National Science Foundation (NSF) last year in the hope of arranging the first joint project. But NSF officials found descriptions of the new programme "vague" and raised a lot of questions. However, a JRDC official in charge of the programme says he is confident a joint project will soon be started.

JRDC has won a budget of Y364 million ( $\$ 2.6$ million) for the programme in fiscal year 1990 . $¥ 280$ million will go to the joint project with the United Kingdom and the rest to a new project. Eventually JRDC officials hope to have about four new projects each year, as in the case of ERATO.

The other joint UK-Japanese project, still under negotiation, is on muon-catalysed fusion and is expected to be carried out at the Rutherford Appleton Laboratory in the United Kingdom. Japan will provide a negative muon channel with superconducting magnets and other peripherals for the high-intensity pulsedmuon source at Rutherford. STA has received preliminary funding for the superconducting channel. The total cost of the project over the next seven years is expected to be about $£ 10$ million.

David Swinbanks \& Peter Aldhous

\section{Still a step from 'Eureka'}

\section{Paris}

FRENCH companies may be shying away from the Eureka programme for marketable European high-technology innovation because of inefficiency in the way it is run. This is one of the conclusions revealed in an independent 'operational audit', commissioned by the government, of about half of the 127 projects in which French industry has a share.

Nevertheless, the survey, carried out by IDS Consultants, a company based in the Paris suburbs, says that Eureka is "an undeniable success", with 297 active projects. But to make sure that French industry continues to be involved in new proposals, Prime Minister Michel Rocard last week unveiled a series of measures designed to improve efficiency in the selection, financing and follow-up of Eureka projects - the main stumblingblocks identified by IDS.

According to the survey, projects may still be "very vague" when they are accorded Eureka status; sometimes evaluations are inadequate and may be contested; some of the projects do not have obvious industrial applications (contrary to Eureka's 1985 Hanover Charter) and, sometimes, 'alibi' partners are brought in to conform to the rule of transfrontier collaboration, although their involvement is not essential.

Companies also criticized the way government grants are managed. More than 89 per cent of respondents complained that backing was not guaranteed for the duration of the project. Sixty per cent felt it took too long for the authorities to agree projects and to sign a contract. About half said the sizes of grants promised by the government were vague and noncommittal, while differences in the ways partner countries finance projects can cause stops and starts. Finally, when there are several sponsors, financial management becomes overcomplicated.

To counter these criticisms, the interministerial Eureka committee, presided over by research minister Hubert Curien, has taken steps to tighten up the administration. More emphasis will be placed on the initial evaluation of proposals, helping companies to define their projects. And once a project is accepted, its evaluation committee will continue to steer developments during its passage to production.

A greater responsibility has also been given to ANVAR (Agence Nationale pour la Valorisation de la Recherche), the governmental agency set up to promote technology innovation. ANVAR will help companies to find foreign partners - one of the main reasons small companies seek Eureka support - and will serve as cashier when there are several sponsors.

The Eureka committee also wants to see greater diversity in the fields of technology covered. So far the most successful projects have been in the electronics sector, such as microchips (JESSI) and high-definition television. In 1990, a push will be made to find new projects in seven target areas: the construction, automobile and railway industries, pharmaceutical and biotechnologies, telecommunications, agriculture and the environment.

Last week, the French Eureka programme also moved out of its probationary period when a new statute established a permanent organization committee, headed by secretary general Henri Guillaume.

Peter Coles 